\title{
Tetramethylpyrazine inhibits tumor growth of lung cancer through disrupting angiogenesis via BMP/Smad/Id-1 signaling
}

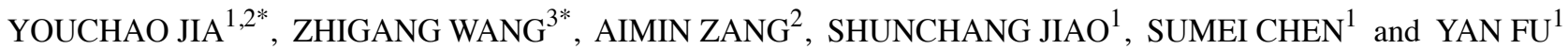 \\ ${ }^{1}$ Department of Medical Oncology, General Hospital of Chinese PLA, Beijing 100853; \\ ${ }^{2}$ Department of Medical Oncology, Affiliated Hospital of Hebei University, Baoding 071000; \\ ${ }^{3}$ Department of Medical Oncology, Baoding Hengxing Hospital of Traditional Chinese \\ and Western Medicine, Baoding 071000, P.R. China
}

Received January 19, 2016; Accepted February 24, 2016

DOI: $10.3892 /$ ijo.2016.3443

\begin{abstract}
The underlying mechanisms of inhibitory effects induced by tetramethylpyrazine (TMP) on angiogenesis and tumor growth of lung cancer were investigated. In vitro cell proliferation, migration, and tube formation of human microvascular endothelial cells (HMEC-1) were evaluated by a 3-(4,5-dimethylthiazol-2-yl)-2,5-dephenyltetrazolium bromide (MTT), wound healing, Transwell, and Matrigel assays. The expression of BMP/Smad/Id-1 signals was detected by RT-PCR and western blotting. In an A549 xenograft tumor model, TMP (40 and $80 \mathrm{mg} / \mathrm{kg} /$ day) was intraperitoneally injected into mice. The expressions of CD31, phosphorylated Smad1/5/8, and Id-1 were measured by immunohistochemistry. We demonstrated that TMP inhibited proliferation, migration, and capillary tube formation of HMEC-1 in a dose- and time-dependent manner. Furthermore, treatment of HMEC-1 cells with TMP $(0.4 \mathrm{mg} / \mathrm{ml})$ significantly upregulated BMP2 expression and downregulated BMPRIA, BMPRII, phosphorylated Smad1/5/8, and Id-1 expression. In addition, administrations of TMP remarkably inhibited tumor growth of A549 xenograft in nude mice. The CD31, phosphorylated Smad1/5/8, and Id-1 expression were significantly inhibited in TMP-treated xenograft tumors compared with the vehicle. In conclusion, our results indicated that TMP suppressed angiogenesis and tumor growth of lung cancer via blocking the BMP/Smad/Id-1 signaling.
\end{abstract}

\section{Introduction}

Lung cancer is the second most common cancer threat to human health and life in the world and its incidence is growing

Correspondence to: Dr Shunchang Jiao, Department of Medical Oncology, General Hospital of Chinese PLA, 28 Fuxing Road, Beijing 100853, P.R. China

E-mail: shunchjiao16@163.com

${ }^{*}$ Contributed equally

Key words: tetramethylpyrazine, angiogenesis, lung cancer, tumor growth, BMP/Smad/Id-1 signaling in many countries (1). Non-small cell lung cancers (NSCLCs) accounts for almost $80 \%$ of all lung cancer cases (2). In recent years, lung cancer is still a great challenge in clinical treatment. Surgery resection is only applicable for the patients with early stage. Due to lack of characteristic clinical manifestations, a majority of lung cancer patients are diagnosed with serious symptoms in the late stages. Moreover, chemo-resistance to many common chemo-agents is emerged in the treatment of lung cancer (3). Therefore, an effective and safe strategy is required for the diagnosis and therapy of lung cancer.

Tetramethylpyrazine (TMP) is one of the active compounds extracted from the Chinese medicinal plant Ligusticum chuanxiong (4). It has been widely used as an active ingredient in the clinical treatment of neurovascular and cardiovascular diseases $(4,5)$. The soluble salts tetramethylpyrazine hydrochloride (TMPH) and TMP phosphate, administrated by injection or oral tablets, have been widely used in clinical treatment (6). The underlying mechanisms involve inhibition of platelet aggregation, suppression of apoptosis, and scavenging peroxyl radicals and superoxide and hydroxyl radicals $(1,7)$. A substantial amount of evidence has revealed that TMP has various biological activities, such as antioxidant activity, antitumor activity including glioma, osteosarcoma, hepatocyte carcinoma, gastric, breast and lung cancer (4,8-13). However, its effectiveness of lung cancer and the molecular mechanisms related to tumor growth are still far from completely known.

The development and metastasis of lung cancer cells are always related to dysregulation of cell proliferation and abnormal tumor microenvironment. The vascular niche acts as a major compartment of tumor microenvironment and has an important role in the initiation, progression and metastasis of tumors. Endothelial cells (ECs) are composed of the majority of vascular cells. The interaction between cancer cells and endothelial cells is associated with the process of angiogenesis within the tumor microenvironment (14). Angiogenesis, the process of new capillary blood vessel formation, is considered to be crucial for growth, maintenance, and metastasis of solid tumor. The strategy of blocking angiogenesis is an effective approach to inhibit tumor growth in lung cancer. It has been investigated that COX-2 is related to the regulation of cancer angiogenesis, which has an effect on the prognosis of patients with non-small cell lung cancer (15). In recent studies, TMP 
has been found to inhibit lung cancer cell proliferation via suppressing cell cycle progression and a significant inhibition of cancer cell invasion and metastasis via COX-2 pathway (1). Moreover, it was reported that the inhibition of neovascularization and fibrosis of microcirculation was mediated by TMP via its regulation of the SDF-1/CXCR4 pathway. These results suggest that TMP may be used as a promising candidate for tumor suppression via angiogenesis. However, the molecular mechanism underlying the TMP functional roles in human lung carcinoma needs to be further investigated. Thus, in this study, we investigated the effect of TMP on angiogenesis and tumor growth of lung cancer.

\section{Materials and methods}

Chemicals and reagents. Tetramethylpyrazine (TMP), L-glutamine, penicillin, streptomycin, noggin, 3- (4,5-dimethylthiazol-2-yl)-2,5-dephenyltetrazolium bromide (MTT), and epidermal growth factor (EGF) were purchased from SigmaAldrich (St. Louis, MO, USA). MCDB131, DMEM culture medium and fetal bovine serum were purchased from Gibco (New York, NY, USA). Horseradish peroxidase (HRP) conjugated anti-rabbit and anti-mouse secondary antibodies were purchased from Santa Cruz Biotechnology (Santa Cruz, CA, USA).

Cell lines and cell culture. Human microvascular endothelial cell line (HMEC-1) was purchased from American Type Culture Collection (Manassas, VA, USA). The cells were maintained in MCDB131 medium, supplemented with $10 \%$ fetal bovine serum, $2 \mathrm{mM}$ L-glutamine, $10 \mathrm{ng} / \mathrm{ml}$ EGF and antibiotics (100 $\mu \mathrm{g} / \mathrm{ml}$ of penicillin, and $100 \mu \mathrm{g} / \mathrm{ml}$ of streptomycin). A549 human NSCLC cell line was obtained from Cell Bank in the Type Culture Collection Center in Chinese Academy of Sciences (Shanghai, China). A549 cell line was cultured in DMEM medium supplemented with $10 \%$ fetal bovine serum and antibiotics. All the cells were maintained in a humidified atmosphere of $5 \% \mathrm{CO}_{2}$ at $37^{\circ} \mathrm{C}$. In all experiments, exponentially growing cells were used.

MTT assay of cell growth. HMEC-1 cell growth was measured by the 3-(4,5-dimethylthiazol-2-yl)-2,5-diphenyltetrazolium bromide assay (MTT) following the manufacturer's instructions. Briefly, cells were incubated in a 96 -well plate at a density of $5 \times 10^{3}$ cells /well with $100 \mu 1$ culture medium. The cells were incubated for $24 \mathrm{~h}$ at $37^{\circ} \mathrm{C}$ with $5 \% \mathrm{CO}_{2}$ in the humidified incubator. The next day, cells were treated with $0,0.2,0.4$ and $0.8 \mathrm{mg} / \mathrm{ml}$ of TMP for 24,48 and $72 \mathrm{~h}$, respectively. At the end of detection time-point, $20 \mu \mathrm{l}$ of MTT solution $(5 \mathrm{mg} / \mathrm{ml})$ was added into each well and incubated for $4 \mathrm{~h}$ at $37^{\circ} \mathrm{C}$ with $5 \% \mathrm{CO}_{2}$ in the humidified incubator. Then the supernatant was discarded and $200 \mu \mathrm{l}$ DMSO was added, followed by incubating for $5 \mathrm{~min}$ on the oscillator. Finally, the optical density (OD) value was measured at a wavelength of $490 \mathrm{~nm}$ using a microplate reader. The OD values of treatment groups were normalized to that of control group.

Wound healing assay. HMEC-1 cells ( $5 \times 10^{5}$ cells/well) were seeded into a 6 -well plate. After incubation for $24 \mathrm{~h}$, a yellow tip was used to create a wound in each well. The cells were incubated with vehicle (control) or new MCDB131 medium containing $0.2,0.4$ and $0.8 \mathrm{mg} / \mathrm{ml}$ of TMP after rinsing with PBS three times. After incubation for $12 \mathrm{~h}$, three randomly selected regions were photographed under a microscope. The distance of the wound was then estimated quantitatively using Image-Pro Plus software. Migration rate was calculated as follows: migration rate $(\%)=\left(\mathrm{D}_{0 \mathrm{~h}}-\mathrm{D}_{12 \mathrm{~h}}\right) / \mathrm{D}_{0 \mathrm{~h}} \times 100 \%$.

Migration assay. The migration assay was further carried out on a Transwell assay using cell culture chambers (Corning, Cambridge, MA, USA). HMEC- 1 cells $\left(2 \times 10^{5}\right.$ cells/well) were cultured in the inner chamber in the vehicle (control) or MDCB 131 medium containing $0.2,0.4$ and $0.8 \mathrm{mg} / \mathrm{ml}$ of TMP. The outer chamber was maintained the same medium with $15 \%$ FBS. After incubated at $37^{\circ} \mathrm{C}$ with in a humidified $5 \% \mathrm{CO}_{2}$ atmosphere for $12 \mathrm{~h}$, the cells in the upper chamber and on the Matrigel were removed mechanically with a cotton swab. The migrated cells adherent to the outer surface of the membrane were fixed with $90 \%$ ethanol and stained using $0.1 \%$ crystal violet, then washed with distilled water till the water was colorless. Images of migrated cells were photographed by microscopy.

Tube formation assay. The effect of TMP on angiogenesis in vitro was measured using the HMEC-1 cells capillary-like tube formation assay. Briefly, a 96-well plate was pre-coated with $50 \mu \mathrm{l}$ Matrigel per well and solidified at $37^{\circ} \mathrm{C}$ for $30 \mathrm{~min}$. HMEC- 1 cells $\left(5 \times 10^{4}\right.$ cells/well) and samples (TMP of $0,0.2$, 0.4 and $0.8 \mathrm{mg} / \mathrm{ml}$ ) were added into each well correspondingly, and incubated for another $12 \mathrm{~h}$. The enclosed capillary networks of tube formation were recorded by an Olympus IX51 digital camera (Tokyo Japan).

RT-PCR. After TMP treatment for $24 \mathrm{~h}$, total RNA was extracted using a TRIzol method according to the manufacture's protocol. Subsequently, first-strand cDNA was synthesized from $1 \mu \mathrm{g}$ of total RNA using avian myeloblastosis virus reverse transcriptase (Takara Biotechnology, Dalian, China). The PCR primers and the corresponding conditions for BMP2, BMP receptor 1A (BMPR1A), BMP receptor 1B (BMPR1B), BMP receptor II (BMPRII), Smad 4, Id-1, and 18S rRNA were based on previous reports $(16,17)$.

Western blotting. Total proteins were extracted and further subjected to concentration determination using the bicinchoninic acid (BCA) protein assay reagent kit (Beyotime Biotechnology, China). Then the total cellular protein extraction was separated using SDS-PAGE gel electrophoresis and transferred to a nitrocellulose membrane (Millipore, USA). After blocking with TBST containing 5\% non-fat milk for $20 \mathrm{~min}$, the membrane was treated with antibodies against Id-1 (Santa Cruz Biotechnology), phospho-Smad1/5/8 Ser ${ }^{463 / 465}$, Smad4 (Cell Signaling Technology, Shanghai, China), and $\beta$-actin (Santa Cruz Biotechnology) overnight at $4^{\circ} \mathrm{C}$. Protein bands were detected by incubation with horseradish peroxidase (HRP)-conjugated secondary antibodies for $1 \mathrm{~h}$, and visualized with SuperSignal Chemiluminescent HRP substrates (Thermo Fisher Scientific, Shanghai, China).

A549 tumor xenografts in nude mice. Male BALB/c nude mice, aged 4-6 weeks, were used in this study and purchased 
A

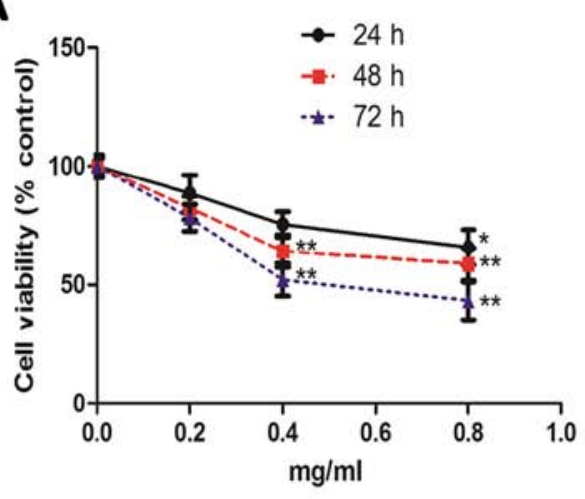

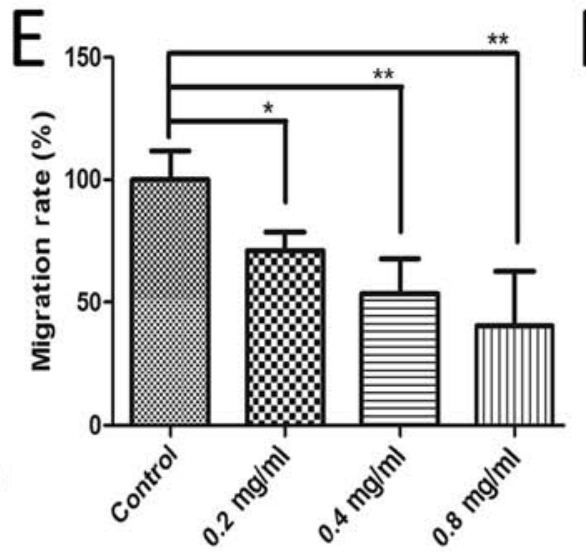
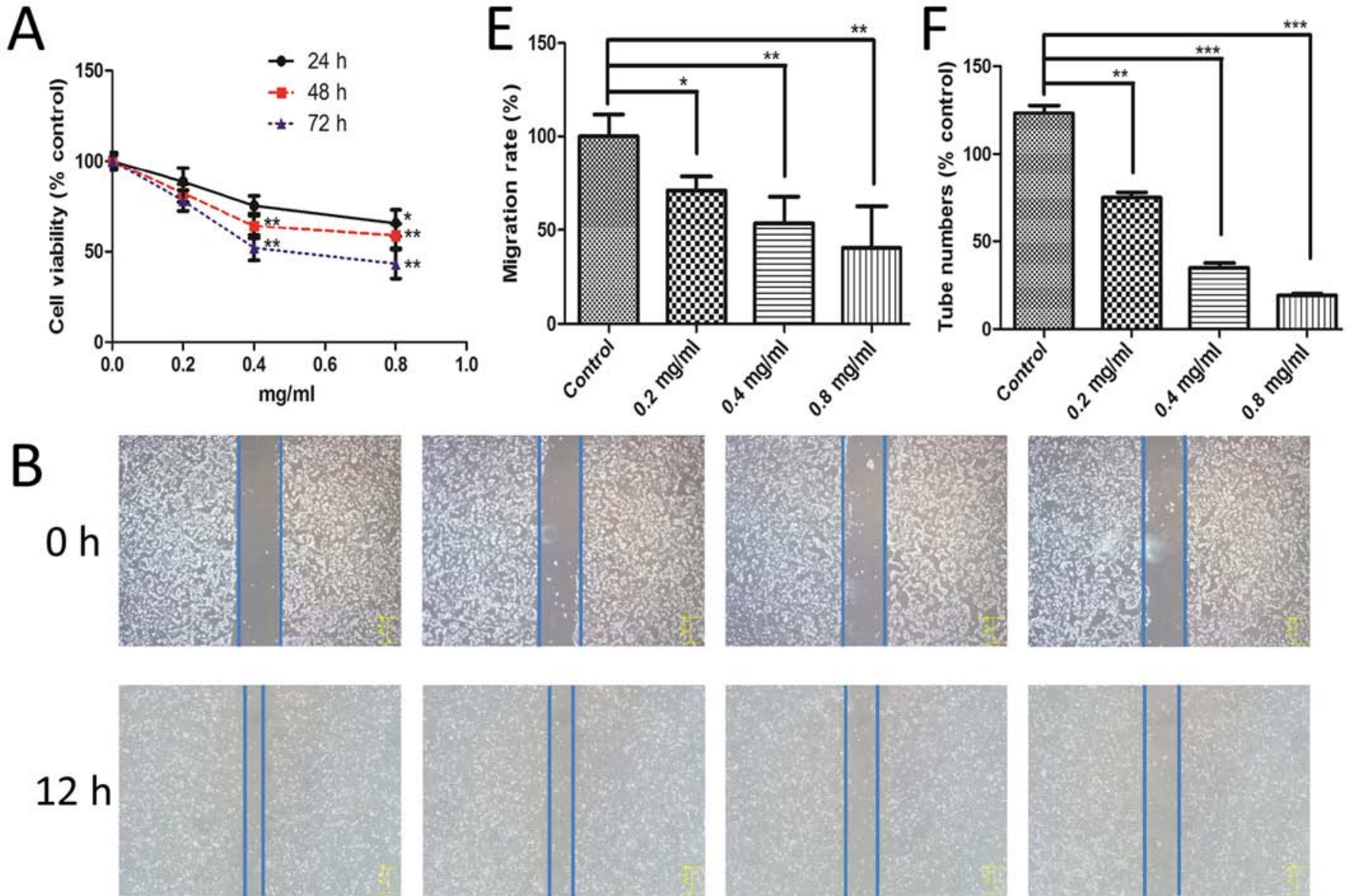

Control

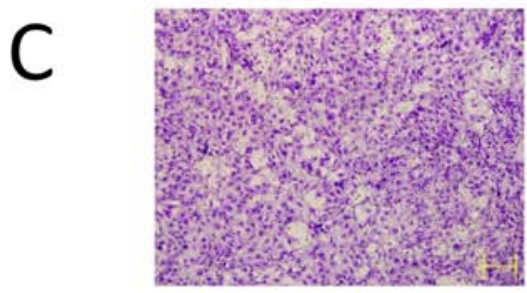

Control
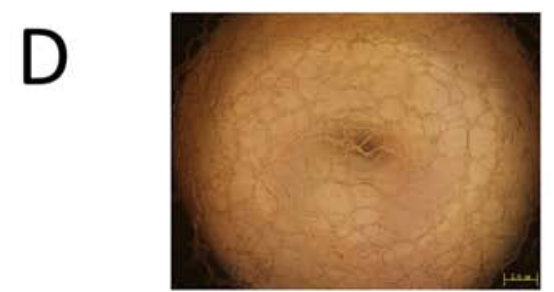

Control
$0.2 \mathrm{mg} / \mathrm{ml}$

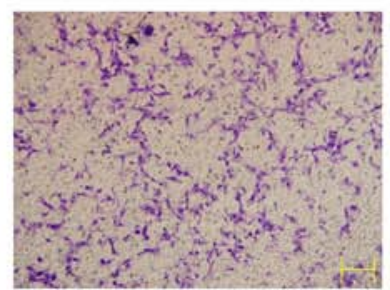

$0.2 \mathrm{mg} / \mathrm{ml}$

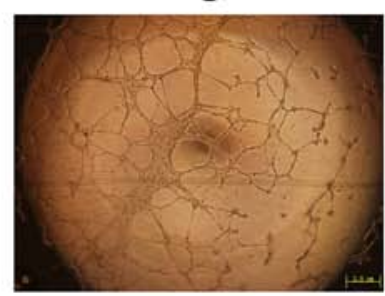

$0.2 \mathrm{mg} / \mathrm{ml}$

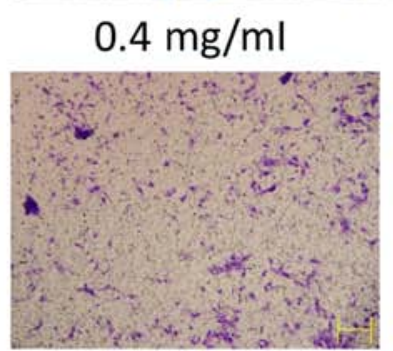

$0.4 \mathrm{mg} / \mathrm{ml}$

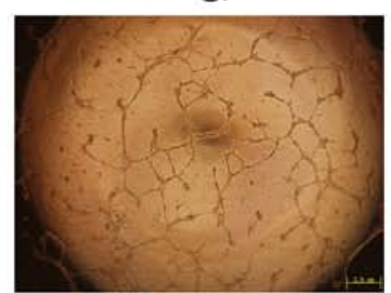

$0.4 \mathrm{mg} / \mathrm{ml}$
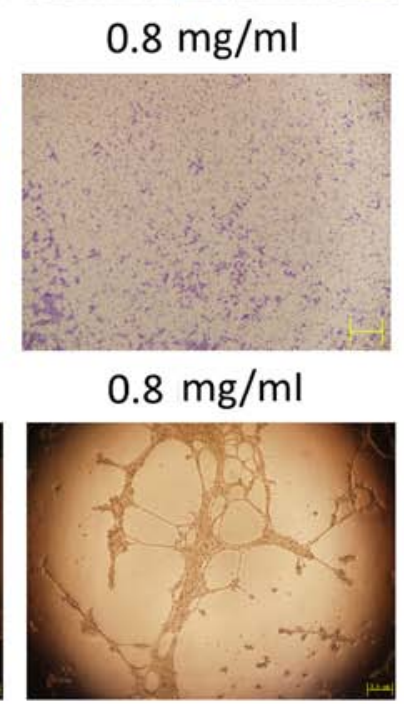

$0.8 \mathrm{mg} / \mathrm{ml}$

Figure 1. The effect of TMP on HMEC-1 cell proliferation, migration, and capillary structure. (A) After $24 \mathrm{~h}$ of incubation, HMEC-1 cells were treated with 0 , $0.2,0.4$ and $0.8 \mathrm{mg} / \mathrm{ml}$ of TMP for 24, 48 and $72 \mathrm{~h}$, respectively. Cell viability was measured by the MTT assay (black solid line for $24 \mathrm{~h}$; red dashed line for 48 $\mathrm{h}$; blue dotted line for $72 \mathrm{~h}$ ). TMP inhibited the migration of HMEC-1 cells in the wound healing assay (B) and a Transwell assay (C). (D) TMP disrupted the tube formation of HMEC-1 cells on Matrigel. HMEC-1 cells were treated with vehicle as the control and 0.2, 0.4 and 0.8 mg/ml TMP for 12 h. (E) Migration rate was calculated from cell migrated distances in the wound healing assay. (F) Capillary tube numbers are shown based on the inhibition of tube formation. Data are presented as mean \pm standard deviation (SD). Statistical analyses were performed using Student's t-test for comparison of two groups. Control stands for vehicle group. ${ }^{*} \mathrm{p}<0.05 \mathrm{vs}$. group of control, ${ }^{* *} \mathrm{p}<0.01 \mathrm{vs}$. group of control, ${ }^{* * * *} \mathrm{p}<0.001$ vs. group of control.

from the Shanghai Laboratory Animal Center. All of the experiments were approved by the Experimental Animal Research Committee of our affiliation. A549 cancer cells $\left(1 \times 10^{6}\right.$ cells $/ 0.2 \mathrm{ml}$ serum-free DMEM medium) were inocu- lated into the right thigh of nude mice. As the tumors reached an average volume of about $100 \mathrm{~mm}^{3}$, the mice were randomized into control and treatment groups with 10 mice each group: a) vehicle; b) TMP (40 mg/kg); c) TMP $(80 \mathrm{mg} / \mathrm{kg})$. 

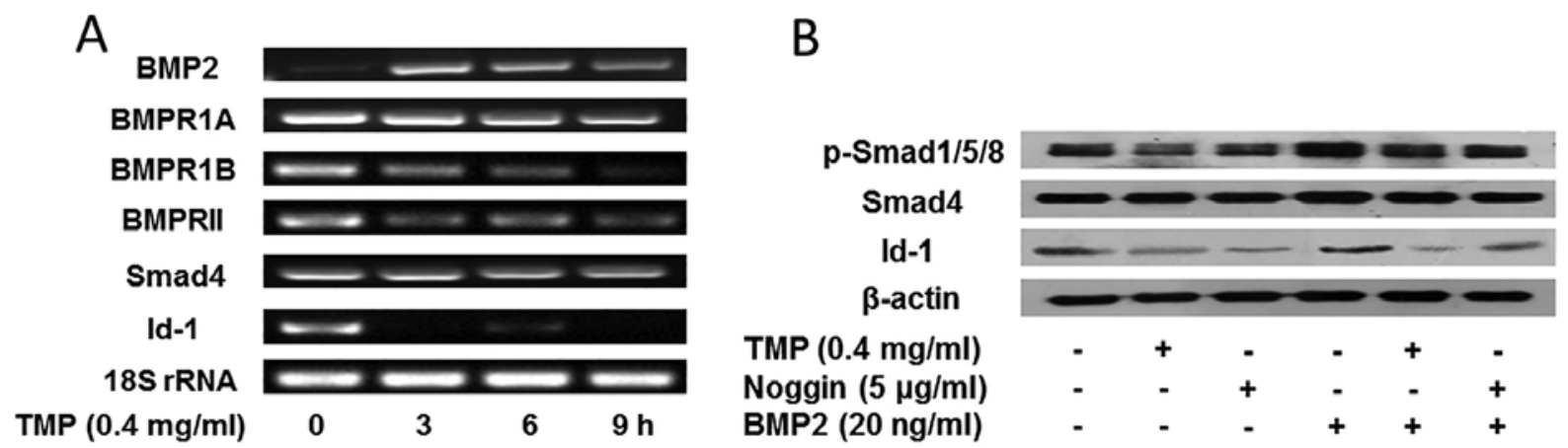

Figure 2. Effect of TMP on BMP/Smad/Id-1 signaling pathway. (A) The expression of BMP2, BMP receptors (BMPR1A, BMPR1B, and BMPRII), Smad 4, Id-1, and 18S rRNA was analyzed by RT-PCR. (B) TMP or noggin inhibited the expression of phosphorylated Smad1/5/8, and Id-1 induced by BMP2 treatment in HMEC-1 cells. The cells were pretreated with vehicle, $0.4 \mathrm{mg} / \mathrm{ml}$ of TMP, and $5 \mu \mathrm{g} / \mathrm{ml}$ of noggin for $24 \mathrm{~h}$, and then with $20 \mathrm{ng} / \mathrm{ml}$ of BMP2 or vehicle for another $4 \mathrm{~h}$. The above mentioned proteins were analyzed by western blotting. $\beta$-actin was used as the control.

TMP was injected intraperitoneally (i.p.) into the mice in the treatment group daily, and mice in control group were subjected to same volume of physiological saline daily. The diet and mental status of the mice were examined every day, and the tumor was measured with a caliper every two days. The tumor volume $\left(\right.$ in $\left.\mathrm{mm}^{3}\right)$ was calculated as follows: volume $=(\text { width })^{2}$ $\mathrm{x}$ length/2.

Immunohistochemistry (IHC). At the end of the experiment, the mice were sacrificed. Then, the xenograft tissues were excised, and fixed in $4 \%$ paraformaldehyde. Next, the tissues were embedded in paraffin, and sectioned for immunohistochemical analysis. The staining was carried out on a section $(5 \mu \mathrm{m})$ of xenograft tissues according to standard methods. We incubated the section in an appropriate dilution of primary antibody against CD31 (Proteintech, Wuhan, China), phosphorylated Smad1/5/8, or Id-1 (1:100) overnight at $4^{\circ} \mathrm{C}$, and subsequently stained them with HRP-conjugated secondary antibody (Santa Cruz Biotechnology). The sections were then visualized with 3,3'-diaminobenzidine and counterstaining with hematoxylin.

Statistical analysis. The results are presented as mean \pm standard deviation (SD). Statistical analyses were performed using Student's t-test for comparison of two groups or one-way analysis of variance (ANOVA) for multiple comparisons by Prism software (GraphPad Software). $\mathrm{P}<0.05$ was considered statistically significant $\left({ }^{*} \mathrm{p}<0.05,{ }^{* *} \mathrm{p}<0.01,{ }^{* * *} \mathrm{p}<0.001\right)$.

\section{Results}

TMP inhibits HMEC-1 cell proliferation, migration and tube formation. Angiogenesis involves multiple steps in endothelial cells, including proliferation, migration, and capillary tube formation. First, we used an MTT assay to study the effect of TMP on HMEC-1 cell proliferation. We observed that TMP exhibited a significant inhibition of HMEC-1 cell proliferation in a time- and dose-dependent manner (Fig. 1A). Moreover, we used a wound healing assay and a Transwell migration assay to evaluate the effect of TMP on the endothelial cell migration. As shown in Fig. 1B and E, after incubated with TMP for $12 \mathrm{~h}$, the cell migration was inhibited significantly compared with the control. This effect of TMP was also observed using the transwell model (Fig. 1C). TMP showed a significant inhibition of cell migration in a dose-dependent manner using both of these methods. Finally, an in vitro Matrigel model was employed to study its effect on tube formation of HMEC-1 cells. The results showed that TMP treatment at $0.4 \mathrm{mg} / \mathrm{ml}$ and $0.8 \mathrm{mg} / \mathrm{ml}$ disrupted the enclosed capillary structures (Fig. 1D). The numbers of capillary networks was significantly decreased after treated with TMP (Fig. 1F). Taken together, the above results showed that TMP inhibited HMEC-1 cell proliferation, migration, and capillary structure formation in vitro.

TMP inhibits BMP/Smad/Id-1 signaling in HMEC-1 cells. As previously reported, the activation of BMP/Smad/Id-1 signaling promoted angiogenesis by upregulation of Id-1 $(18,19)$. In order to investigate whether the inhibition of angiogenesis by TMP was due to the blocking of BMP/Smad/Id-1 signaling in HMEC-1 cells, we evaluated the effect of TMP $(0.4 \mathrm{mg} / \mathrm{ml})$ on the signaling pathway. As shown in Fig. 2A, an increased expression of BMP2 was observed in the prior stage of TMP treatment, whereas, a slightly decreased expression of BMP2 was emerged after treatment for $9 \mathrm{~h}$. Additionally, a significant reduction of BMP2 receptor BMPR1B, and BMPRII was observed, while, the receptor BMPR1A did not alter obviously. Furthermore, TMP showed little effect on the expression of Smad4. However, the expression of Id-1 decreased significantly after TMP treatment. The results indicated that TMP modulated the BMP2 expression, and blocked its receptors (BMPR1A and BMPRII), further downregulating Id-1 expression. In order to confirm the role of Smad molecules in the modulation of Id-1, we further investigated the effect of TMP on the phosphorylation of Smad1/5/8 and Id-1 expression. It was observed (Fig. 2B) that TMP showed downregulation of the phosphorylation of $S \operatorname{mad} 1 / 5 / 8$, but no significant inhibition on Smad4. Moreover, the Id-1 expression was significantly decreased after treated with TMP $(0.4 \mathrm{mg} /$ $\mathrm{ml}$ ). Actually, the effect of TMP blocking BMP/Smad/Id-1 signaling was similar to that of noggin, an endogenous BMP2 antagonist (Fig. 2B). Together, these results suggested that TMP may inhibit angiogenesis via blocking the BMP/Smad/ Id-1 signaling in HMEC-1 cells. 
A
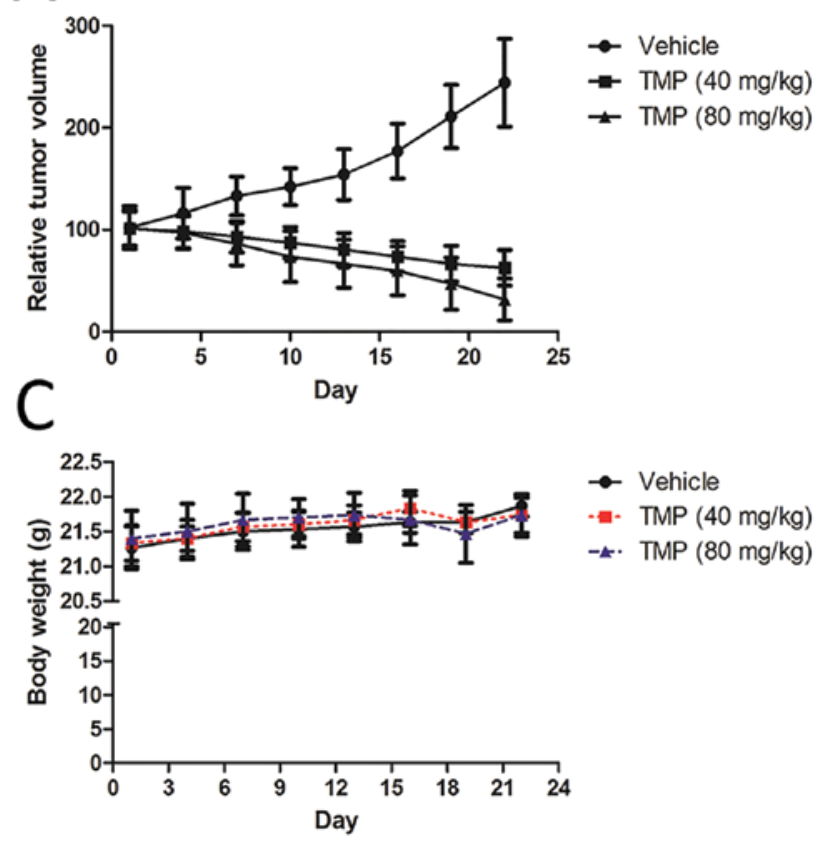

B

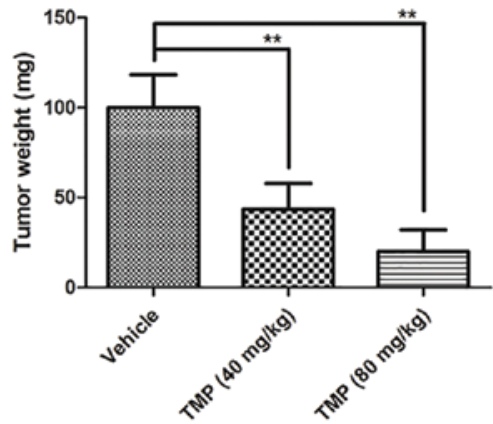

Figure 3. TMP suppressed the tumor growth of A549 xenograft in nude mice. (A) Human lung cancer cells A549 were inoculated into the right thigh of nude mice. As the tumors reached an average volume $\sim 100 \mathrm{~mm}^{3}$, the mice were randomized into three groups: a) vehicle; b) TMP (40 mg/kg); c) TMP (80 mg/kg). TMP or same volume of saline was injected intraperitoneally (i.p.) into the mice daily. The diet and mental status of the mice were examined every day, and the tumor was measured with a caliper every two days. The tumor volume $\left(\right.$ in $\left.\mathrm{mm}^{3}\right)$ was calculated as follows: volume $=(\text { width })^{2} \mathrm{x}$ length $/ 2$. $(\mathrm{B}) \mathrm{The}$ tumor weight was significantly inhibited in the xenograft model. Control stands for vehicle group. " $\mathrm{p}<0.05$ vs. group of control, ${ }^{* * *} \mathrm{p}<0.01$ vs. group of control. (C) The body weights of the three groups showed no significant differences during the experiments [black solid line for vehicle; red dotted line for TMP (40 mg/kg); blue dashed line for TMP $(80 \mathrm{mg} / \mathrm{kg})]$
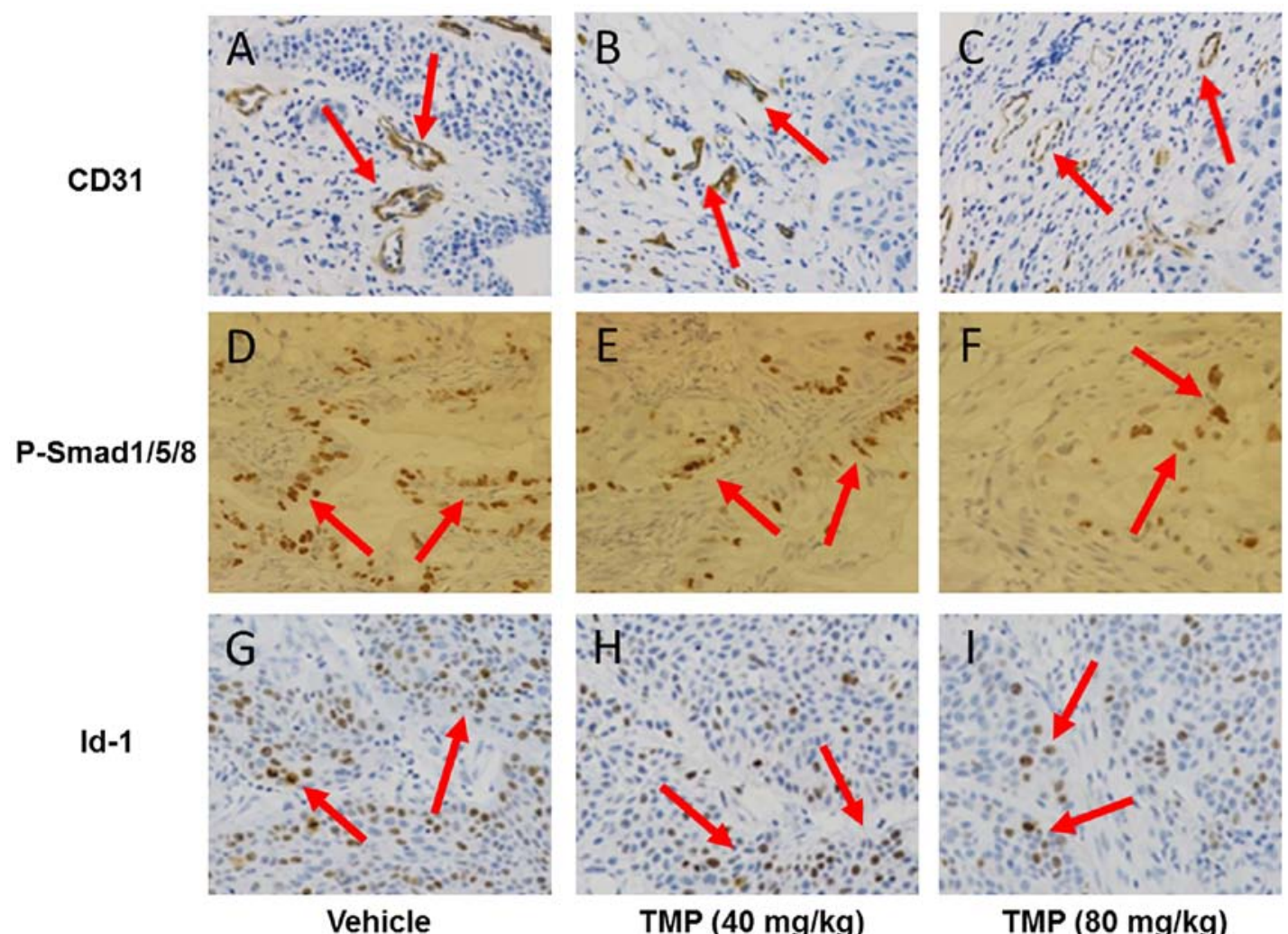

Vehicle

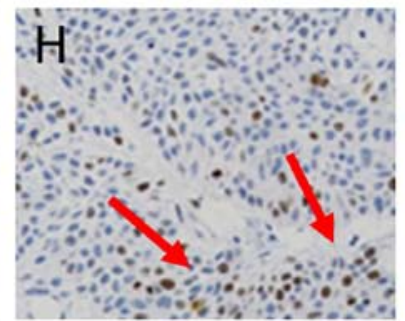

TMP $(40 \mathrm{mg} / \mathrm{kg})$

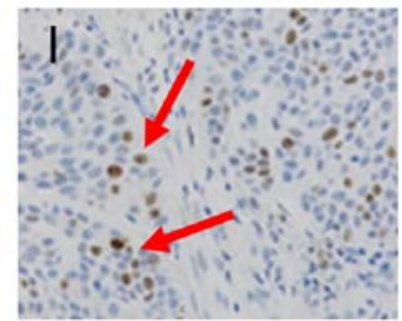

TMP $(80 \mathrm{mg} / \mathrm{kg})$

Figure 4. CD31, phosphorylated Smad1/5/8, and Id-1 expression reduced significantly in the TMP-treated tumor tissues. Immunohistochemistry method was carried out on the tumor tissues after sacrifice of the TMP-treated $(40$ and $80 \mathrm{mg} / \mathrm{kg}$ ) and vehicle-treated mice. Compared with the vehicle (A), CD31 expression reduced significantly in the tumor tissues treated with $40 \mathrm{mg} / \mathrm{kg}$ TMP (B), and $80 \mathrm{mg} / \mathrm{kg}$ TMP (C). The expression of phosphorylated Smad1/5/8 was also lower in the treatment of $40 \mathrm{mg} / \mathrm{kg}$ TMP (E), and $80 \mathrm{mg} / \mathrm{kg}$ TMP (F), compared with the vehicle (D). The expression of Id-1 was decreased in the treatment of $40 \mathrm{mg} / \mathrm{kg}$ TMP $(\mathrm{H})$, and $80 \mathrm{mg} / \mathrm{kg}$ TMP (I), compared with the vehicle (G). All images are at x200 magnification. 
TMP inhibits the growth of A549 xenograft nude mice. To further evaluate the anti-angiogenic activity of TMP in vivo, we used an A549 lung cancer cell line xenograft tumor model. As shown in Fig. 3A, a low and high dose of TMP (40, and $80 \mathrm{mg} / \mathrm{kg} / \mathrm{day}$ ) was intraperitoneally administered into the mice. After 22-day treatment, TMP significantly inhibited the growth of A549 xenograft in nude mice, compared to the vehicle group (Fig. 3A). In addition, the tumor weight of TMP-treated groups was remarkably decreased compared to the vehicle-treated group (Fig. 3B). However, the body weight of the mice did not show any significant change in any of the A549 xenograft nude mice during the experiments (Fig. 3C).

TMP inhibits BMP/Smad/Id-1 signaling in A549 xenograft nude mice. In order to confirm the in vivo anti-angiogenic activity of TMP via BMP/Smad/Id-1 signaling, we used an immunohistochemical assay to detect the expression of CD31, phosphorylation of Smad1/5/8, and Id-1 expression in the A549 tumor tissues. CD31 is a positive biomarker related to microvessel density in endothelial cells. As shown in Fig. 4A-C, the CD31 expression of TMP treatment (40 and $80 \mathrm{mg} / \mathrm{kg} / \mathrm{day}$ ) was significantly reduced in the tumor tissues compared to the vehicle-treated tumor tissues. The result suggested that TMP also had an anti-angiogenic activity in vivo. Interestingly, we also observed downregulation of phosphorylated Smad1/5/8 expression in the TMP-treated tumor tissues (Fig. 4D-F). Moreover, the expression of Id-1 in the tumor tissues was also decreased after TMP treatment (Fig. 4G-I). These results indicated that suppression of A549 xenograft in nude mice may be attributed to the impairment of angiogenesis via blocking the $\mathrm{BMP} / \mathrm{Smad} / \mathrm{Id}-1$ signaling.

\section{Discussion}

In this study, we demonstrated that tetramethylpyrazine (TMP) could potently inhibit HMEC-1 cell proliferation and migration in vitro, and capillary structures of HMEC-1 cells using Matrigel model. Most importantly, the inhibition of angiogenesis was found to be associated with the blockade of BMP/Smad/Id-1 signaling, suggesting that the BMP/Smad/ Id-1 signaling was a potential target of TMP.

The blood vessel circulatory system fuels the neighboring tissues with nutrients and oxygen. A proper formation of blood vessels is necessary for cell and tissue growth. Thus, the disruption of tube formation has been used as an effective strategy to inhibit tumor growth (20). Angiogenesis involves multiple steps, including vasodilation, basement membrane degradation, endothelial cell migration, endothelial cell proliferation, and capillary tube formation (21). As described in the previous study, TMP significantly decreases migration and tube formation in human umbilical endothelial cell line ECV304 (6). Our results demonstrated that TMP remarkably inhibited human microvascular endothelial cell (HMEC-1) proliferation, migration, and capillary structure formation compared with the control (Fig. 1). In addition, the inhibition of angiogenesis by TMP was dose- and time-dependent.

BMPs are secreted extracellular signaling ligands of the transforming growth factor $\beta$ (TGF- $\beta$ ) family, including four groups: i) the BMP2 and -4 subgroup; ii) the growth and differ- entiation factor (GDF) $5,-6$, and -7 group; iii) the BMP5, -6, -7, and -8 group; and iv) the BMP9 and -10 group (20). Originally, the BMPs were discovered due to their ability to induce bone and cartilage formation (22). Subsequently, BMPs were also found to have an important role in the development of blood vessels. Accumulating evidence has demonstrated that BMPs are essential for angiogenic processes by binding to their receptors on the cells, such as endothelial and smooth muscle cells (22). It is reported that BMP2 can enhance angiogenesis in melanoma (23). The angiogenic effect is exerted via the signaling triggered by the BMP type I receptor (BMP1A, and BMP1B) and BMPRII. Most importantly, it has been demonstrated that BMPRII is required for maintenance of vascular integrity (24). The result obtained in this study demonstrated upregulated BMP2 expression, and downregulated BMPR1B and BMPRII expression after TMP treatment. Interestingly, the expression of BMP2 was upregulated after $3 \mathrm{~h}$ of treatment with TMP. However, BMP2 was subsequently decreased slightly after $9 \mathrm{~h}$ of the treatment. We hypothesize that TMP compete with BMP2 to bind with BMPs receptors. Thus, BMPR1B and BMPRII expression are downregulated in the early stage of TMP treatment, corresponding to the upregulation of BMP2 expression. Whereas, with the downregulation of BMP receptors (BMPR1B and BMPRII), the expression of BMP2 was further decreased slightly. Actually, this hypothesis still needs to be confirmed by future study.

BMP signal binding to type I and II transmembrane serine/ threonine kinase type receptors further triggers phosphorylation of the receptor-regulated Smads, such as Smad1, -5 , and -8 , and initiation of the canonical or Smad-mediated pathway (20). The other Smads involved in the BMP signaling include the common-mediator Smad4 and the inhibitory Smad6, and -7 $(25,26)$. Once activated, the phosphorylated Smad $1 / 5 / 8$ forms a hetero complex with Smad4, and translocates into the nucleus, where they interact with different co-activators, repressors, then positively or negatively regulate transcription of target genes, such as the genes for $I d-1$ (inhibitor of differentiation- 1 or inhibitor of DNA binding-1), inhibitory Smads (Smad6 and -7), and Serpinel (plasminogen activator inhibitor-1) (27). Id-1 activated by BMPs is crucial for the stimulation of endothelial cells (28). In addition, loss of Id-1 has been demonstrated to result in the downregulation of proangiogenic genes in tumor endothelial cells (29). It suggests that Id-1 has an important role in tumor metastasis via promoting angiogenesis (30). The expression of Smad4 did not show any significant changes in our data (Fig. 2A). On the contrary, the phosphorylation of Smad1/5/8 was downregulated significantly after treated with TMP at $0.4 \mathrm{mg} / \mathrm{ml}$ (Fig. 2B). Most importantly, the expression of Id-1 decreased significantly induced by the treatment of TMP (Fig. 2), whereas, the effect of TMP on the BMP/Smad/ Id-1 signaling was similar to that of BMP2 antagonist noggin (Fig. 2B).

In addition, Id-1 has a pivotal role in cell proliferation, differentiation, invasion, and metastasis $(31,32)$. Further, TMP-exerted anti-A549 activity in vivo was confirmed by the A549 xenografts in nude mice. The inhibitory effect of TMP on the growth of A549 lung cancer cells in nude mice was attributed to the inhibition of tumor growth (Fig. 3A and B). Moreover, inhibition of angiogenesis in tumor tissues was also demonstrated. CD31, a well-established biomarker in endothe- 
lial cells, is appropriate for evaluating angiogenesis (33-35). Compared with the control, the CD31 expression was significantly reduced in the TMP-treated mice (Fig. 4A-C), which suggested that the angiogenesis was also inhibited by TMP in the A549 tumor xenograft model. The in vivo result was in accordance with that of in vitro result (Fig. 1). Furthermore, the expression of phosphorylated Smad1/5/8, and Id-1 in the TMP-treated tumor tissues was lower than that of vehicletreated tissues. Thus, TMP was confirmed to inhibit BMP/ Smad/Id-1 signaling in vivo.

In conclusion, in this study, we illustrated that TMP was a potent angiogenesis inhibitor. This anti-angiogenic activity was correlated with the blockade of BMP/Smad/Id-1 signaling. In addition, TMP presented a significant inhibition of the nude mouse tumor xenograft model of A549 human lung cancer cells. Hence, TMP may be a potential drug candidate for human lung cancer therapy.

\section{Acknowledgements}

This study was supported by Medical Science Research Project of Hebei Province Health Department (grant no. ZD20140221).

\section{References}

1. Zheng CY, Xiao W, Zhu MX, Pan XJ, Yang ZH and Zhou SY: Inhibition of cyclooxygenase-2 by tetramethylpyrazine and its effects on A549 cell invasion and metastasis. Int J Oncol 40: 2029-2037, 2012.

2. Yan JH, Zhao CL, Ding LB and Zhou X: FOXD3 suppresses tumor growth and angiogenesis in non-small cell lung cancer. Biochem Biophys Res Commun 466: 111-116, 2015.

3. Zhengfu H, Hu Z, Huiwen M, Zhijun L, Jiaojie Z, Xiaoyi $\mathrm{Y}$ and Xiujun $\mathrm{C}$ : 1-o-acetylbritannilactone (ABL) inhibits angiogenesis and lung cancer cell growth through regulating VEGF-Src-FAK signaling. Biochem Biophys Res Commun 464: 422-427, 2015.

4. Yi B, Liu D, He M, Li Q, Liu T and Shao J: Role of the ROS/ AMPK signaling pathway in tetramethylpyrazine-induced apoptosis in gastric cancer cells. Oncol Lett 6: 583-589, 2013.

5. Zheng Z, Li Z, Chen S, Pan J and Ma X: Tetramethylpyrazine attenuates TNF- $\alpha$-induced iNOS expression in human endothelial cells: Involvement of Syk-mediated activation of PI3K-IKK-I $\mathrm{B}$ signaling pathways. Exp Cell Res 319: 2145$2151,2013$.

6. Cai X, Chen Z, Pan X, Xia L, Chen P, Yang Y, Hu H, Zhang J, $\mathrm{Li} \mathrm{K}$, Ge J, et al: Inhibition of angiogenesis, fibrosis and thrombosis by tetramethylpyrazine: Mechanisms contributing to the SDF-1/CXCR4 axis. PLoS One 9: e88176, 2014.

7. Wang X-Y, Ma Z-C, Wang Y-G, Tan HL, Xiao CR, Liang QD, Tang XL, Cheng Y and Gao Y: Tetramethylpyrazine protects lymphocytes from radiation-induced apoptosis through nuclear factor- $\kappa$ B. Chin J Nat Med 12: 730-737, 2014.

8. Cao J, Miao Q, Miao S, Bi L, Zhang S, Yang Q, Zhou X, Zhang M, Xie Y, Zhang J, et al: Tetramethylpyrazine (TMP) exerts antitumor effects by inducing apoptosis and autophagy in hepatocellular carcinoma. Int Immunopharmacol 26: 212-220, 2015.

9. Chen Z, Pan X, Georgakilas AG, Chen P, Hu H, Yang Y, Tian S, Xia L, Zhang J, Cai X, et al: Tetramethylpyrazine (TMP) protects cerebral neurocytes and inhibits glioma by down regulating chemokine receptor CXCR4 expression. Cancer Lett 336: 281-289, 2013

10. Yan Y, Zhao J, Cao C, Jia Z, Zhou N, Han S, Wang Y, Xu Y, Zhao J, Yan Y, et al: Tetramethylpyrazine promotes SH-SY5Y cell differentiation into neurons through epigenetic regulation of Topoisomerase II $\beta$. Neuroscience 278: 179-193, 2014.

11. Kim M, Kim S-O, Lee M, Lee JH, Jung WS, Moon SK, Kim YS, Cho KH, Ko CN and Lee EH: Tetramethylpyrazine, a natural alkaloid, attenuates pro-inflammatory mediators induced by amyloid $\beta$ and interferon- $\gamma$ in rat brain microglia. Eur J Pharmacol 740: 504-511, 2014.
12. Zhang Y, Liu X, Zuo T, Liu Y and Zhang JH: Tetramethylpyrazine reverses multidrug resistance in breast cancer cells through regulating the expression and function of P-glycoprotein. Med Oncol 29: 534-538, 2012.

13. Yan YX, Zhao JX, Han S, Zhou NJ, Jia ZQ, Yao SJ, Cao CL, Wang YL, Xu YN, Zhao J, et al: Tetramethylpyrazine induces SH-SY5Y cell differentiation toward the neuronal phenotype through activation of the PI3K/Akt/Sp1/TopoII $\beta$ pathway. Eur J Cell Biol 94: 626-641, 2015

14. Du H, Shi H, Chen D, Zhou Y and Che G: Cross-talk between endothelial and tumor cells via basic fibroblast growth factor and vascular endothelial growth factor signaling promotes lung cancer growth and angiogenesis. Oncol Lett 9: 1089-1094, 2015.

15. Li Y, Li S, Sun D, Song L and Liu X: Expression of 15-hydroxyprostaglandin dehydrogenase and cyclooxygenase- 2 in non-small cell lung cancer: Correlations with angiogenesis and prognosis. Oncol Lett 8: 1589-1594, 2014.

16. Cejalvo T, Sacedón R, Hernández-López C, Diez B, GutierrezFrías C, Valencia J, Zapata AG, Varas A and Vicente A: Bone morphogenetic protein-2/4 signalling pathway components are expressed in the human thymus and inhibit early T-cell development. Immunology 121: 94-104, 2007.

17. Ling MT, Wang X, Tsao SW and Wong YC: Down-regulation of Id-1 expression is associated with TGF beta 1-induced growth arrest in prostate epithelial cells. Biochim Biophys Acta 1570: 145-152, 2002.

18. Qiu H, Yang B, Pei ZC, Zhang Z and Ding K: WSS25 inhibits growth of xenografted hepatocellular cancer cells in nude mice by disrupting angiogenesis via blocking bone morphogenetic protein (BMP)/Smad/Id1 signaling. J Biol Chem 285: 32638-32646, 2010.

19. Song X, Liu S, Qu X, Hu Y, Zhang X, Wang T and Wei F: BMP2 and VEGF promote angiogenesis but retard terminal differentiation of osteoblasts in bone regeneration by up-regulating Id1. Acta Biochim Biophys Sin (Shanghai) 43: 796-804, 2011.

20. Beets K, Huylebroeck D, Moya IM, Umans L and Zwijsen A: Robustness in angiogenesis: Notch and BMP shaping waves. Trends Genet 29: 140-149, 2013.

21. Bao P, Kodra A, Tomic-Canic M, Golinko MS, Ehrlich HP and Brem H: The role of vascular endothelial growth factor in wound healing. J Surg Res 153: 347-358, 2009.

22. Wang S, Cai R, Ma J, Liu T, Ke X, Lu H and Fu J: The natural compound codonolactone impairs tumor induced angiogenesis by downregulating BMP signaling in endothelial cells. Phytomedicine 22: 1017-1026, 2015.

23. Rothhammer T, Bataille F, Spruss T, Eissner G and Bosserhoff AK: Functional implication of BMP4 expression on angiogenesis in malignant melanoma. Oncogene 26: 4158-4170, 2007.

24. Liu D, Wang J, Kinzel B, Müeller M, Mao X, Valdez R, Liu Y and Li E: Dosage-dependent requirement of BMP type II receptor for maintenance of vascular integrity. Blood 110: 15021510,2007

25. Wu MY and Hill CS: TGF-beta superfamily signaling in embryonic development and homeostasis. Dev Cell 16: 329-343, 2009.

26. Conidi A, Cazzola S, Beets K, Coddens K, Collart C, Cornelis F, Cox L, Joke D, Dobreva MP, Dries R, et al: Few Smad proteins and many Smad-interacting proteins yield multiple functions and action modes in TGF $\beta /$ BMP signaling in vivo. Cytokine Growth Factor Rev 22: 287-300, 2011

27. Morikawa M, Koinuma D, Miyazono K and Heldin CH: Genomewide mechanisms of Smad binding. Oncogene 32: 1609-1615, 2013.

28. Valdimarsdottir G, Goumans MJ, Rosendahl A, Brugman M, Itoh S, Lebrin F, Sideras P and ten Dijke P: Stimulation of Id1 expression by bone morphogenetic protein is sufficient and necessary for bone morphogenetic protein-induced activation of endothelial cells. Circulation 106: 2263-2270, 2002.

29. Fong S, Debs RJ and Desprez PY: Id genes and proteins as promising targets in cancer therapy. Trends Mol Med 10: 387-392, 2004

30. Ling MT, Wang X, Zhang X and Wong YC: The multiple roles of Id-1 in cancer progression. Differentiation 74: 481-487, 2006.

31. Fong S, Itahana Y, Sumida T, Singh J, Coppe JP, Liu Y, Richards PC, Bennington JL, Lee NM, Debs RJ, et al: Id-1 as a molecular target in therapy for breast cancer cell invasion and metastasis. Proc Natl Acad Sci USA 100: 13543-13548, 2003. 
32. Wang X, Xu K, Ling MT, Wong YC, Feng HC, Nicholls J and Tsao SW: Evidence of increased Id-1 expression and its role in cell proliferation in nasopharyngeal carcinoma cells. Mol Carcinog 35: 42-49, 2002.

33. Biswas S, Charlesworth PJ, Turner GD, Leek R, Thamboo PT, Campo L, Turley H, Dildey P, Protheroe A, Cranston D, et al: CD31 angiogenesis and combined expression of HIF-1a and HIF- $2 \alpha$ are prognostic in primary clear-cell renal cell carcinoma (CC-RCC), but HIF $\alpha$ transcriptional products are not: Implications for antiangiogenic trials and HIFa biomarker studies in primary CC-RCC. Carcinogenesis 33: 1717-1725, 2012 .
34. Miyata Y, Sagara Y, Watanabe S, Asai A, Matsuo T, Ohba K, Hayashi T and Sakai H: CD105 is a more appropriate marker for evaluating angiogenesis in urothelial cancer of the upper urinary tract than CD31 or CD34. Virchows Arch 463: 673-679, 2013.

35. Kim SJ, Kim JS, Papadopoulos J, Wook Kim S, Maya M, Zhang F, He J, Fan D, Langley R and Fidler IJ: Circulating monocytes expressing CD31: Implications for acute and chronic angiogenesis. Am J Pathol 174: 1972-1980, 2009. 